\title{
Patent ductus arteriosus: current clinical status
}

In 1959, Burnard first drew attention to the association of patent ductus arteriosus (PDA) and premature birth when he reported that PDA murmurs could be heard more frequently in prematurely born infants than in those born at term. ${ }^{1}$ Subsequent reports by Powell, ${ }^{2}$ Danilowicz et al., ${ }^{3}$ and Auld ${ }^{4}$ indicated that, although PDA may commonly cause clinical signs in infants born before term, the ductus almost always closes spontaneously. In 1971, Girling and Hallidie-Smith reported an incidence of PDA of $19 \%$ among infants born before 36 weeks' gestation at the Hammersmith Hospital; ${ }^{5}$ the incidence was higher in infants with respiratory distress syndrome (RDS). In their series, medical treatment of the PDA failed in only one of 38 patients. The next year, Kitterman et al. reported a similar incidence of PDA among infants with birthweights $1750 \mathrm{~g}$ or less born at the University of California, San Francisco during the years 1967 to 1970.6 They also noted a higher incidence in patients with RDS. However, in their group, spontaneous closure occurred in only 16 of 29 infants; 10 infants underwent operative closure and 3 died with a PDA. During the last 12 years the incidence of PDA at that hospital has been higher (Table), and approximately one-third of those infants with PDA have required operative or pharmacological closure of their PDA.

Other authors have reported a similar high incidence of PDA among prematurely born infants, ${ }^{7-10}$ but they differ in the proportion in whom medical treatment fails. In our experience, PDA is most troublesome among very small infants with severe RDS in whom the murmur can be heard in the first 2 days of life. In two studies in which ligation was rarely done, ${ }^{9-10}$ infants who died before 60 and 72 hours of age respectively, were excluded; thus, it is possible that infants most likely to develop uncontrollable heart failure were not included in these reports.

The reasons for the increased incidence of PDA among infants born prematurely appear to be related to a higher rate of survival for these infants,

Table Patent ductus arteriosus among infants $\leq 1750 \mathrm{~g}$ born at University of California, San Francisco 1967-78 inclusive

\begin{tabular}{lllll}
\hline $\begin{array}{l}\text { Total } \\
\text { infants }\end{array}$ & Survived & $\begin{array}{l}\text { No. with } \\
P D A\end{array}$ & $\begin{array}{l}\text { Incidence } \\
\text { of PDA }\end{array}$ & $\begin{array}{l}\text { No. with ligation } \\
\text { or indomethacin }\end{array}$ \\
\hline 451 & 325 & 142 & $31.4 \%$ & $\begin{array}{l}44(31 \% \text { of those } \\
\text { with PDA) }\end{array}$ \\
\hline
\end{tabular}

particularly those with RDS. ${ }^{11}$ Incidence of PDA is inversely related to birthweight and gestational age. ${ }^{8}$ These associations and the relation to RDS (due to immaturity of the lungs) indicate that immaturity of the ductus is a major factor. In immature infants there is less ductal muscle, ${ }^{12}$ and the subendothelial cushions, which obliterate the lumen when the ductus constricts, are absent. ${ }^{13}$ In recent years, there has been stricter control of inspired oxygen to prevent high levels of arterial $\mathrm{Po}_{2}$ because of the risk of retrolental fibroplasia. This may be an additional factor in the higher incidence of PDA, as the muscle of the immature ductus shows less contraction in response to oxygen than that of the mature ductus. ${ }^{14-15}$ Another likely contributing factor is increased fluid intake which has been associated with ductal patency in two reports. ${ }^{716}$

Recent studies suggest that prostaglandins may be important. ${ }^{17-18}$ Overdistention of the dog lung releases prostaglandin $E$ from the lung. ${ }^{19}$ An intriguing possibility is that treatment of the atelectasis of RDS with positive pressure may stimulate release of prostaglandin $E$ and thus contribute to ductal patency; however, data supporting this concept are lacking. (For further discussion, see preceding Annotation.)

The diagnosis of a large PDA is relatively straightforward in infants without pulmonary disease. Such infants exhibit typical cardiac signs and, in low birthweight infants, other forms of congenital heart disease are relatively rare. ${ }^{20}$ When RDS is present, the diagnosis is not easy as the murmur may be difficult to hear, ${ }^{21}$ and evaluation of other signs-such as tachycardia, tachypnoea, and retractions-is complicated by the presence of pulmonary disease. In such infants, a widened aortic pulse pressure measured through an umbilical arterial catheter may be the first sign of a clinically important PDA. ${ }^{22}$ Silverman and associates showed that echocardiagraphic measurement of left atrial size, compared with the aortic root, is an accurate indication of the magnitude of ductal shunting in most cases. ${ }^{23}$ The method has the advantages of being noninvasive, rapid, and easily performed repeatedly as the infant's condition changes; although in some cases it gives results at variance with clinical findings. ${ }^{24}$ Other diagnostic techniques reported to be helpful, but not as widely used, are aortography, ${ }^{21}$ Doppler ultrasonic measurement of brachial arterial flow, ${ }^{25}$ and analysis of aortic diastolic pressure. ${ }^{26}$ 
Much discussion has been directed to the question of whether the ductus may cause worsening or prolongation of the course of RDS. ${ }^{6}{ }^{27-28}$ Haemodynamic studies in RDS indicate that left-to-right shunting through the ductus is small or nonexistent before 24 hours of age, ${ }^{29-30}$ but that after this time large left-to-right ductal shunts are common. ${ }^{30}$ However, the contribution of these shunts to the pulmonary disease remains uncertain.

PDA has been associated with necrotising enterocolitis, ${ }^{10} \mathbf{3 1}$ a condition in which bowel ischaemia plays an important role. With a large ductal shunt, decreased blood flow to the bowel is probably caused by the large aortic runoff into the pulmonary circulation, and possibly by decreased cardiac output due to the effects of diastolic hypotension resulting in decreased myocardial oxygenation $^{32}$ and myocardial necrosis. ${ }^{33}$

In most cases, medical treatment is adequate to sustain the infant until the ductus closes spontaneously. Identification of those who will require more active intervention to close the ductus is often difficult and the subject of debate. If continued ductal shunting is a cause of progressive pulmonary disease in some infants, early recognition is essential. Conversely, careful selection is necessary to avoid unnecessary operative or pharmacological intervention. There is a relatively large number of infants who have RDS and who seem to have a moderate-sized ductal shunt but no clear evidence of heart failure; in these, the RDS frequently runs a prolonged, chronic course. Since the report of Siassi et al. ${ }^{28}$ several authors have inferred that the prolonged lung disease results from chronic pulmonary oedema and have advocated early intervention to close the ductus in such cases. ${ }^{634-37}$ Although one prospective, random study supports this view, ${ }^{38}$ further data are needed to resolve this point.

Ligation of PDA in small preterm infants has been widely reported and has an extremely low operative mortality ${ }^{6-7} 34$ 39-41 In those with slight RDS or no lung disease, ligation leads to rapid improvement in cardiorespiratory function and almost all survive. In contrast, when PDA coexists with severe RDS, improvement after ligation is slower and mortality is relatively high due to progressive pulmonary disease and other complications of prematurity.

Because of these problems, investigators have sought nonoperative methods of closing the ductus. Increased environmental oxygen has been suggested ${ }^{42}$ but is contraindicated in most preterm infants because of the potential risk of retrolental fibroplasia. Acetylcholine was shown to constrict the ductus but the effect was too short-lived to be clinically useful. ${ }^{43}$ More recently, inhibitors of prostaglandin synthesis have been used. After studies which showed that E prostaglandins relax ductal muscle, ${ }^{44}$ Coceani et al. produced in vitro contraction of ductal muscle with inhibitors of prostaglandin synthesis. ${ }^{45}$ Subsequent studies showed that these inhibitors produced intrauterine constriction of the ductus arteriosus in rats $^{46}$ and lambs. ${ }^{47}$ Shortly thereafter, two clinical studies (Friedman et al. ${ }^{17}$ and Heymann et al. ${ }^{18}$ ) showed that indomethacin, a potent inhibitor of prostaglandin synthesis, was effective in constricting the ductus arteriosus in most prematurely born infants with PDA. Lucas and Mitchell found raised plasma prostaglandin levels in infants with PDA; 48 the prostaglandin levels were unaffected by ductal ligation but decreased after treatment with indomethacin, supporting the concept that endogenous prostaglandins have a part in maintaining ductal patency in infants born before term.

Not all prematurely born infants with PDA respond to indomethacin. Neal and associates found it effective in only 2 of 11 patients with severe RDS. ${ }^{49}$ Other authors have reported a low rate of ductal closure when indomethacin is given after 14 days of age ${ }^{50-52}$ The reason for failure of treatment with indomethacin in these cases is unknown; it suggests that factors other than prostaglandins are responsible in some cases of PDA.

As prostaglandins are distributed throughout the body, systemic administration of inhibitors of prostaglandin synthesis could be expected to have widespread effects. To date, the only serious complication commonly reported is transient renal insufficiency which appears to be dose related and is accompanied by oliguria, azotaemia, raised creatinine concentration, and hyperkalaemia. ${ }^{17-1852} \mathrm{~A}$ few cases of gastrointestinal bleeding have been described ${ }^{53-54} \mathrm{It}$ is surprising that bleeding problems have not been more common because indomethacin markedly decreases platelet aggregation, and normal function does not return until several days after indomethacin treatment. ${ }^{53}$ As indomethacin in blood is tightly bound to albumin,${ }^{55}$ it may displace bilirubin and should not be used in jaundiced infants $;^{17}$ so far there have been no reported cases of kernicterus associated with indomethacin. Recent studies indicate that indomethacin decreases release of pulmonary surfactant into the alveolar space of adult and fetal rabbits; ;6-57 further research is essential to determine if these results in experimental animals have clinical relevance. Because of the uncertainties about indomethacin, several authors have urged caution in its use and have stated that it should be used only in controlled clinical trials until more data are available on its efficacy and on the incidence and type of complications. ${ }^{58-60}$

In summary, PDA is a common and a serious 
clinical problem among prematuraly born infants. Uncertainties about PDA persist regarding aetiology, diagnosis, its role in severe RDS, selection of patients for intervention, and the method of interventionligation, indomethacin, or perhaps a newer, more effective pharmacological agent.

\section{References}

1 Burnard F D. A murmur that may arise from the ductus arteriosus in the human baby. Proc R Soc Med 1959; 52: 77-8.

2 Powell M L. Patent ductus arteriosus in premature infants. Med J Aust 1963; 2: 58-60.

3 Danilowicz D, Rudolph A M, Hoffman J I E. Delayed closure of the ductus arteriosus in premature infants. Pediatrics 1966; 37: 74-8.

4 Auld P A M. Delayed closure of the ductus arteriosus. J Pediatr 1966; 69: 61-6.

5 Girling D J, Hallidie-Smith K A. Persistent ductus arteriosus in ill and premature babies. Arch Dis Child 1971; 46: 177-81.

6 Kitterman J A, Edmunds L H, Jr, Gregory G A, Heymann M A, Tooley W H, Rudolph A M. Patent ductus arteriosus in premature infants: incidence, relation to pulmonary disease, and management. $N$ Engl J Med 1972; 287: 473-7.

7 Zachman R D, Steinmetz G P, Botham R J, Graven S N, Ledbetter M K. Incidence and treatment of the patent ductus arteriosus in the ill premature neonate. Am Heart $J$ 1974; 87: 697-703.

${ }^{8}$ Siassi B, Blanco C, Cabal L A, Coran A G. Incidence and clinical features of patent ductus arteriosus in lowbirthweight infants: a prospective analysis of 150 consecutively born infants. Pediatrics $1976 ; 57$ : 347-51.

9 Clarkson P M, Orgill A A. Continuous murmurs in infants of low birth weight. J Pediatr 1974; 84: 208-11.

10 Cotton R B, Stahlman M T, Kovar I, Calterton W Z. Medical management of small preterm infants with symptomatic patent ductus arteriosus. $J$ Pediatr 1978; 92: 467-73.

11 Gregory G A, Kitterman J A, Phibbs R H, Tooley W H, Hamilton W K. Treatment of the idiopathic respiratorydistress syndrome with continuous positive airway pressure. N Engl J Med 1971; 284: 1333-40.

12 Imamura H, Okamoto N, Satow Y, Hidaka N, Akimoto $\mathbf{N}$. Closure of the ductus arteriosus in normal and malformed human heart. Hiroshima J Med Sci 1978; 27: 47-59.

13 Desligneres S, Larroche J C. Ductus arteriosus. Biol Neonate 1970; 16: 278-96.

14 McMurphy D M, Heymann M A, Rudolph A M, Melmon K L. Developmental changes in constriction of the ductus arteriosus: responses to oxygen and vasoactive agents in the isolated ductus arteriosus of the fetal lamb. Pediatr Res 1972; 6: 231-8.

15 Clyman R I, Mauray F, Wong L, Heymann M A, Rudolph A M. The developmental response of the ductus arteriosus to oxygen. Biol Neonate $1978 ; 34: 177-81$.

16 Stevenson J G. Fluid administration in the association of patent ductus arteriosus complicating respiratory distress syndrome. J Pediatr 1977; 90: 257-61.

17 Friedman W F, Hirschklau M J, Printz M P, Pitlick P T, Kirkpatrick S E. Pharmacologic closure of patent ductus arteriosus in the premature infant. N Engl J Med 1976; 295: 526-9.

18 Heymann M A, Rudolph A M, Silverman N H. Closure of the ductus arteriosus in premature infants by inhibition of prostaglandin synthesis. N Engl J Med 1976; 295: 530-3.

19 Said S I, Kitamura S, Vriem C. Prostaglandins: release from the lung during mechanical ventilation at large tidal volumes (abstract). J Clin Invest 1972; 51: 83-4A.

20 Levin D L, Stanger P, Kitterman J A, Heymann M A. Congenital heart disease in low birth weight infants. Circulation 1975; 52: 500-3.

21 Thibeault D W, Emmanouilides G C, Nelson R J, Lachman R S, Rosengart R M, Oh W. Patent ductus arteriosus complicating the respiratory distress syndrome in preterm infants. J Pediatr 1975; 86: 120-6.

22 Kitterman J A, Phibbs R H, Tooley W H. Catheterization of umbilical vessels in newborn infants. Pediatr Clin North Am 1970; 17: 895-912.

23 Silverman N H, Lewis A B, Heymann M A, Rudolph A M. Echocardiographic assessment of ductus arteriosus shunt in premature infants. Circulation $1974 ; 50: 821-5$.

24 Hirschklau M J, DiSessa T G, Higgins C B, Friedman W F. Echocardiographic diagnosis: pitfalls in the premature infant with a large patent ductus arteriosus. $J$ Pediatr 1978; 92: 474-7.

25 Feldtman R W, Andrassy R J, Alexander J A, Stanford W. Doppler ultrasonic flow detection as an adjunct in the diagnosis of patent ductus arteriosus in premature infants. J Thorac Cardiovasc Surg 1976; 72: 288-90.

26 Milstein J M, Riemenschneider T A, Goetzman B W, George L, Wennberg R P. Assessment of patent ductus arteriosus shunting using diastolic pressure analysis. J Pediatr 1979; 94: 122-6.

27 Stahlman M. Treatment of cardiovascular disorders of the newborn. Pediatr Clin North Am 1964; 11 : 363-400.

28 Siassi B, Emmanouilides G C, Cleveland R J, Hirose F. Patent ductus arteriosus complicating prolonged assisted ventilation in respiratory distress syndrome. $J$ Pediatr 1969; 74: 11-9.

29 Rudolph A M, Drorbaugh J E, Auld P A M, et al. Studies on the circulation in the neonatal period. The circulation in the respiratory distress syndrome. Pediatrics 1961; 27: 551-66.

30 Stahlman M, Blankenship W J, Shepard F M, Gray J, Young W C, Malan A F. Circulatory studies in clinical hyaline membrane disease. Biol Neonate 1972; 20: 300-20.

31 Kitterman J A. In: Moore T D, ed. Necrotizing enterocolitis in the newborn infant. Report of the sixty-eighth Ross Conference on Pediatric Research. Columbus, Ohio: Ross Laboratories 1975: 38-40.

32 Hoffman J I E, Buckberg G D. Regional myocardial ischemia-causes, prediction, and prevention. Vasc Surg 1974; 8: 115-31.

33 de Sa D J. Myocardial changes in immature infants requiring prolonged ventilation. Arch Dis Child 1977; 52: 138-47.

34 Gay J H, Daily W J R, Meyer B H P, Trump D S, Cloud $D T$, Molthan $M$ E. Ligation of the patent ductus arteriosus in premature infants. Report of 45 cases. $J$ Pediatr Surg 1973; 8: 677-83.

35 Kilman J W, Kakos G S, Williams T E, Jr, Craenan J, Hosier D M. Ligation of patent ductus arteriosus for persistent respiratory distress in premature infants. J Pediatr Surg 1974; 9: 277-81.

3 s Clarke D R, Paton B C, Way G L, Stewart J R. Patent ductus arteriosus ligation and respiratory distress syndrome in premature infants. Ann Thorac Surg 1976; 22: $138-45$.

37 Cooke R W I, Gribbin B, Gunning A J, Pickering D. Ligation of patent ductus arteriosus in the very low birthweight newborn infant. Arch Dis Child 1978; 53: 271-5.

38 Cotton R B, Stahlman M T, Bender H W, Graham T P, Catterton W Z, Kovar I. Randomized trial of early closure of symptomatic patent ductus arteriosus in small preterm infants. J Pediatr 1978; 93: 647-51. 
39 Edmunds L H, Jr, Gregory G A, Heymann M A, Kitterman J A, Rudolph A M, Tooley W H. Surgical closure of the ductus arteriosus in premature infants. Circulation 1973; 48: 856-63.

40 Murphy D A, Outerbridge E, Stern L, Karn G M, Jegier W, Rosales J. Management of premature infants with patent ductus arteriosus. J Thorac Cardiovasc Surg $1974 ; 67: 221-8$.

41 Coran A G, Cabal L, Siassi B, Rosenkrantz J G. Surgical closure of patent ductus arteriosus in the premature infant with respiratory distress. J Pediatr Surg 1975; 10: 399-404.

42 Dunn P M, Speidel B D. Letter: Use of oxygen to close patent ductus arteriosus in preterm infants. Lancet $1973 ; 2$ : 333-4.

43 Heymann M A, Rudolph A M. Constriction of the ductus arteriosus by acetylcholone in premature infants (abstract). Circulation 1971; 43 and 44: Supplement 2, 177.

44 Coceani F, Olley $P$ M. The response of the ductus arteriosus to prostaglandins. Can J Physiol Pharmacol 1973; 51: 220-5.

45 Coceani F, Olley P M, Bodach E. Lamb ductus arteriosus: effect of prostaglandin synthesis inhibitors on the muscle tone and the response to prostaglandin $\mathrm{E}_{2}$. Prostaglandins 1975; 9: 299-308.

46 Sharpe G L, Thalme B, Larsson K S. Studies on closure of the ductus arteriosus. XI. Ductal closure in utero by a prostaglandin synthetase inhibitor. Prostaglandins 1974; 8: 363-9.

47 Heymann M A, Rudolph A M. Effects of acetylsalicylic acid on the ductus arteriosus and circulation in fetal lambs in utero. Circ Res 1976; 38: 418-22.

48 Lucas A, Mitchell M D. Plasma prostaglandins in preterm neonates before and after treatment for patent ductus arteriosus. Lancet $1978 ; 2: 130-2$.

49 Neal W A, Kyle J M, Mullett M D. Failure of indomethacin therapy to induce closure of patent ductus arteriosus in premature infants with respiratory distress syndrome. J Pediatr 1977; 91: 621-3.

50 McCarthy J S, Zies L G, Gelband H. Age-dependent closure of the patent ductus arteriosus by indomethacin. Pediatrics 1978; 62: 706-12.
51 Cooke R W I, Pickering D. Poor response to oral indomethacin therapy for persistent ductus arteriosus in very low birthweight infants. Br Heart $J$ 1979; 41: 301-3.

52 Halliday H L, Hirata T, Brady J P. Indomethacin therapy for large patent ductus arteriosus in the very low birth weight infant: results and complications. Pediatrics 1979; 64: 154-9.

53 Friedman Z, Whitman V, Maisels M J, Berman W, Jr, Marks K H, Vesell E S. Indomethacin disposition and indomethacin-induced platelet dysfunction in premature infants. J Clin Pharmacol 1978; 18: 272-9.

54 Harnick E, van Ertbruggen I, Senders R C, Moulaert A J. Letter: Problems with indomethacin for ductus closure. Lancet 1977; 2: 245.

55 Mason P W, McQueen E G. Protein binding of indomethacin: binding of indomethacin to human plasma albumin and its displacement from binding by ibuprofen, phenylbutazone, and salicylate in vitro. Pharmacology 1974; 12: 12-19.

56 Oyarzun M J, Clements J A. Control of lung surfactant by ventilation, adrenergic mediators, and prostaglandins in the rabbit. Am Rev Respir Dis 1978; 117: 879-92.

57 Bustos R, Ballejo G, Giussi G, Rosas R, Isa J C. Inhibition of fetal lung maturation by indomethacin in pregnant rabbits. J Perinat Med 1978; 6: 240-5.

58 Nadas A S. Patent ductus revisited. $N$ Engl J Med 1976; 295: 563-5.

59 Sharpe G L, Altshuler G. Ductal manipulation-a note of caution. J Pediatr 1977; 90: 335-7.

60 Freidman W F, Heymann M A, Rudolph A M. Commentary: New thoughts on an old problem-patent ductus arteriosus in the premature infant. $J$ Pediatr 1977; 90: $338-40$.

Joseph A KITTERMAN

Department of Pediatrics, University of California, San Francisco, California 94143, USA 